\title{
Aberrant Expression of Citrate Synthase is Linked to Disease Progression and Clinical Outcome in Prostate Cancer
}

This article was published in the following Dove Press journal: Cancer Management and Research

\author{
Zhiduan Cai, ${ }^{1}, *$ Yulin Deng, ${ }^{1} *$ \\ jianheng Ye, ${ }^{2}$ Yangjia Zhuo, ${ }^{3}$ \\ Zezhen Liu, ${ }^{2}$ Yingke Liang, ${ }^{3}$ Hui \\ Zhang, ${ }^{3}$ Xuejin Zhu, ${ }^{2}$ Yong \\ Luo, ${ }^{3}$ Yuanfa Feng, ${ }^{4}$ Ren Liu, ${ }^{2}$ \\ Guo Chen, (iD ${ }^{5}$ Yongding Wu, ${ }^{3}$ \\ Zhaodong Han, ${ }^{3}$ Yuxiang \\ Liang, ${ }^{3}$ Funeng Jiang, ${ }^{3}$ Weide \\ Zhong (D) ${ }^{1-4,6}$
}

'Guangdong Provincial Institute of Nephrology, Nanfang Hospital, Southern Medical University, Guangzhou 5105 I5, People's Republic of China; ${ }^{2}$ Department of Urology, Guangdong Key Laboratory of Clinical Molecular Medicine and Diagnostics, Guangzhou First People's Hospital, Guangzhou Medical University, Guangzhou 5I0180, People's Republic of China;

${ }^{3}$ Department of Urology, Guangdong Key Laboratory of Clinical Molecular Medicine and Diagnostics, Guangzhou First People's Hospital, School of Medicine, South China University of Technology, Guangzhou 510180, People's Republic of China; ${ }^{4}$ Urology Key Laboratory of Guangdong Province, The First Affiliated Hospital of Guangzhou Medical University, Guangzhou Medical University, Guangzhou 510230, People's Republic of China; ${ }^{5}$ Department of Urology, The First Affiliated Hospital of Jinan University, Guangzhou, Guangdong 510632, People's Republic of China; 'School of Medicine, Jinan University, Guangzhou, Guangdong 510632, People's Republic of China

*These authors contributed equally to this work

Correspondence: Weide Zhong Guangdong Provincial Institute of Nephrology, Nanfang Hospital, Southern Medical University, Guangzhou 5I05I5,

People's Republic of China

Email zhongwd2009@live.cn
Purpose: Citrate synthase (CS) is a rate-limiting enzyme in the citrate cycle and is capable of catalyzing oxaloacetate and acetyl-CoA to citrate. CS has been uncovered to be upregulated in a variety of cancers, and its expression and clinical significance in prostate cancer (PCa) remain unknown.

Methods: In this study, we examined the association between CS expression level and clinicopathological features of prostate cancer patients in a TMA cohort and the public cancer database (The Cancer Genome Atlas-Prostate Adenocarcinoma, TCGA-PRAD). The CS knockdown cell lines were constructed to study the effects of CS downregulation on proliferation, colony formation, migration, invasion, and cell cycle of prostate cancer cells in vitro. And the effect of CS downregulation on tumor growth in mice was studied in vivo. In addition, the metabolomics and mitochondrial function were detected in the CS knockdown cell lines.

Results: CS expression level in PCa tissues was higher than that in normal tissues $(P<$ 0.05). CS upregulation was significantly associated with high Gleason score $(P<0.05)$, advanced pathological stage $(P<0.001)$, and biochemical recurrence $(P<0.001)$. Functionally, decreased expression of CS inhibited PCa cell proliferation, colony formation, migration, invasion and cell cycle in vitro, and inhibited tumor growth in vivo. In addition, CS downregulation exerted potential inhibitory effects on the lipid metabolism and mitochondrial function of PCa cells.

Conclusion: In conclusion, these findings suggested that CS upregulation may contribute to the aggressive progression and poor prognosis of PCa patients, which might be partially associated with its influences on the cell lipid metabolism and mitochondrial function.

Keywords: prostate cancer, citrate synthase, prognosis, lipid metabolism

\section{Introduction}

Prostate cancer (PCa) is the most common cancer and the major cause of cancerrelated death among men in 46 countries around the world. ${ }^{1}$ Based on the latest cancer statistics, there would be 174,650 new PCa patients and 31,620 PCa associated deaths in the United States in 2019, ranking first in male cancer incidence and second in male cancer mortality. ${ }^{2}$ Due to the decreased use of PSA (Prostate-Specific Antigen) screening, the overall incidence rate of PCa has declined in the last few years, which may mask the occurrence of the advanced PCa and lead to the stabilization of PCa mortality following the decline of these years. ${ }^{3}$ Therefore, it is a great challenge to identify potential diagnostic markers and therapeutic targets for PCa. 
Dysregulation of metabolism has been revealed to be linked with carcinogenesis and the progression of PCa. Normal prostate cells accumulate zinc, as well as inhibit the oxidation of citric acid and the metabolism of the tricarboxylic acid (TCA) cycle. ${ }^{4}$ In particular, epithelial cells in the normal peripheral zone of the prostate are set to produce citric acid and inhibit the oxidation of citric acid. ${ }^{5,6}$ In contrast, PCa cells actively oxidize citric acid and restore the classic TCA cycle function. ${ }^{4}$ Thus, understanding the metabolic differences between noncancer and cancer cells of the prostate may be of clinical significance to identify novel diagnostic and therapeutic targets for $\mathrm{PCa}$ patients.

The TCA cycle, also known as the citric acid cycle or the Krebs cycle, is a sequence of chemical reactions that release stored energy by oxidative conversion of acetylCoA into adenosine triphosphate (ATP) and carbon dioxide. Citrate synthase (CS), present in almost all living cells, functions as a limiting velocity enzyme in the first step of the CAC cycle. ${ }^{7}$ Accumulating studies have indicated that CS activity may be involved in various cancers. ${ }^{8-10}$

In $\mathrm{PCa}$, Mycielska et al reported that PC-3M cells metabolized citric acid in the cytoplasm by aconitase and fatty acid synthase to heighten their metastatic behavior. ${ }^{11} \mathrm{CS}$ has been shown to be upregulated in prostate circulating tumor cells (CTCs), while other enzymes in the TCA cycle were not elevated. ${ }^{12}$ However, the expression pattern of CS and its roles in prostate carcinogenesis, progression, and prognosis remained unknown. To solve this problem, we examined the association between CS expression level and clinicopathological features of prostate cancer patients in a TMA cohort and the public cancer database (The Cancer Genome Atlas-Prostate Adenocarcinoma, TCGAPRAD). The CS knockdown cell lines were constructed to study the effects of CS downregulation on proliferation, colony formation, migration, invasion, cell cycle of prostate cancer cells in vitro. And the effect of CS downregulation on tumor growth in mice was studied in vivo. In addition, the metabolomics and mitochondrial function were detected in the CS knockdown cell lines.

\section{Materials and Methods}

\section{Patients and Tissues}

PCa tissue microarray (TMA; Creative Bioarray, USA; Cat. No: PRTMA053), which included 71 cases of prostate adenocarcinoma, 2 prostate leiomyosarcoma, 1 prostate hyperplasia and 6 normal prostate tissues, was used for immunohistochemistry analysis. The TMA contained patients' age, Gleason score, Gleason grade, TNM (Tumor Node Metastasis), clinical stage, and pathology grade. No chemotherapy or radiotherapy was given to the patient prior to surgery. Detail informations of the TMA cohort were provided in Supplementary Material. A total of $498 \mathrm{PCa}$ tissues and paired clinical data from the public database (TCGA-PRAD, The Cancer Genome Atlas-Prostate Adenocarcinoma: https://www.cancer.gov/ tcga) were used to evaluate the associations between CS expression level and patients' clinical-pathological features of PCa patients.

\section{Cell Line Culture}

The human PCa cell lines DU145 and PC3 were obtained from American Type Culture Collection (ATCC, USA) and respectively cultured in Dulbecco's Modified Eagle Medium (DMEM; Gibco, USA; Cat. No: C11965500BT) and Roswell Park Memorial Institute (RPMI) 1640 medium (Gibco, USA; Cat. No: C11875500BT) which were added with $10 \%$ fetal bovine serum (FBS; Gibco, USA; Cat.10270-106), $0.1 \mathrm{mg} / \mathrm{mL}$ streptomycin and $100 \mathrm{U} / \mathrm{mL}$ penicillin (Gibco, USA; Cat. No: 15,140-122). The cells were placed in a wettish incubator containing $5 \% \mathrm{CO}_{2}$ at $37^{\circ} \mathrm{C}$. A lentivirus containing the short hairpin RNA of CS or control vector (HYY, China) was used to establish the CS knockdown (CS-sh) cell line or negative control (CT) cell line. The DU145 and PC3 cell lines were infected with the lentivirus and infection agent Polybrene (Santa Cruz, USA; Cat. No: sc-134,220). The stable cell lines were selected through puromycin screening $(3 \mu \mathrm{g} / \mathrm{mL})$ two days after transfection.

\section{Immunohistochemistry}

The protein expression levels of CS in PCa and normal prostate tissues were examined by IHC based in our TMA cohort according to the protocol of our previous report. ${ }^{13,14}$ The immunostaining was obtained using the IHC kit (UltraSensitive ${ }^{\mathrm{TM}}$ SP, MX Biotechnologies, China; Cat. No: KIT-9730) based on the manufacturer's instructions. Rabbit anti-CS (1: 100) were obtained from Boster company (China; Cat. No: BM5202,). The percentage of positively stained cells was calculated and classified as zero $(0-5 \%)$, one $(6-25 \%)$, two $(26-50 \%)$, three $(51-75 \%)$, and four $(76-100 \%)$. The intensity of staining was categorized as zero (negative), one (weak), two 
(moderate), and three (strong). The immunoreactivity score (IRS) was calculated by multiplying the staining percentage and intensity score.

\section{Western Blot Assay}

CS protein expression levels in the PCa CT cells and CSsh cells were examined by Western blot assay based on our previous report. ${ }^{13,14}$ A rabbit anti-CS primary antibody (Boster company, China; Cat. No: BM5202,) was used to detect CS expression level, and a mouse anti- $\beta$-actin primary antibody (Boster company, China; Cat. No: BM0627) was used as a control. The results were visualized with the PXi 9 chemiluminescent detection system (Syngene, England) and analyzed by using ImageJ $1.52 \mathrm{a}$ (Wayne Rasband, USA).

\section{RT-qPCR Assay}

Total RNA was isolated from prostate tissues by RNeasy mini kit (QIAGEN, Germany; Cat. No: 74,104) and reverse transcripted with RT reagent kit (TaKaRa, Japan; Cat. NR037A). Then the cDNA products were used for real-time PCR with the Fast SYBR ${ }^{\circledR}$ Green Master Mix (Life technology, USA; Cat. No: 4,385,610). The primers were as follows: CS forward, 5'- CCCTTTCCGACC CTTACCTG; CS reverse, 5'- CTGGAACAACCCGTC CTGAG; $\beta$-actin forward, 5'- AGCGAGCATCCCCCA AAGTT; $\beta$-actin reverse, 5'- GGGCACGAAGGCT CATCATT. The $\beta$-actin mRNA expression level was used as a control for normalization. The results were analyzed using the comparative cycle threshold method.

\section{Cell Proliferation Assay}

Cell Counting Kit-8 (Meilunbio, China; Cat. No: MA0218-5000) was used to test the cell proliferation. The 96-well plate was seeded with $2000 \mathrm{PCa}$ CT cells or CS-sh cells per well. $10 \mu \mathrm{L} \mathrm{CCK-8} \mathrm{solution} \mathrm{was} \mathrm{added} \mathrm{to}$ each well at 5 time points respectively $(4,24,48,72$ and 96h). The plate was placed in the incubator for 2 hours at $37^{\circ} \mathrm{C}$. The absorbance of the medium at $450 \mathrm{~nm}$ was detected by a microplate reader (Bio-Rad, USA) every day.

\section{Colony Formation Assay}

$500 \mathrm{PCa}$ CT cells or CS-sh cells per well was seeded in the 6-well plate. Cells were cultured with the normal medium for two weeks. The medium was replaced every two days. Then the cells were fixed and stained with $0.1 \%$ crystal violet at room temperature for half an hour. The results were photographed with a camera, and the number of colonies was counted.

\section{Cell Migration and Invasion Assays}

The PCa CT cells or CS-sh cells was seeded in the 6-well plate and reached approximately $90 \%$ confluence for migration assay. After treated with medium without FBS for 24 hours, a $200 \mu \mathrm{L}$ sterile pipette tip was used to make scratches on each well. Photos were taken every 12 hours to observe the healing of scratches using a microscope camera. The scratch healing area was calculated using ImageJ. For invasion assay, $100 \mu \mathrm{L} /$ well Matrigel (BD Biosciences, USA; Cat. No: 354,234) was coated into the upper compartment of the chamber, which was placed into the 24-well plate (Corning, USA; Cat. No: 3422). The upper compartment of the chamber was seeded with 5 x $10^{4}$ cells suspended in $100 \mu \mathrm{L}$ serum-free medium. The lower chamber was added with $500 \mu \mathrm{L}$ normal medium containing 10\% FBS. After incubation for 24 hours, the cells on the upper side of the membrane were removed with a cotton swab. The membrane was fixed with $4 \%$ paraformaldehyde and dyed with $0.1 \%$ crystal violet at room temperature for half an hour. The photos of the invading cells were taken by the microscope camera and counted the cells of five random fields. The experiment was repeated three times.

\section{Cell Cycle Assay}

PCa CT cells or CS-sh cells was seeded in the 6-well plate and reached approximately $70-80 \%$ confluence for the cell cycle assay. The cells were collected and fixed in $70 \%$ ethyl alcohol at $-20{ }^{\circ} \mathrm{C}$ all-night. Then the cells were resuspended in phosphate-buffered saline (PBS), which contained $20 \mu \mathrm{g} / \mathrm{mL}$ PI, $200 \mu \mathrm{g} / \mathrm{mL}$ RNaseA, and $0.1 \%$ Triton $\mathrm{X}-100$. The suspension was incubated in a dark place for half an hour at $4{ }^{\circ} \mathrm{C}$. Flow cytometer (BD FACSVerse, BD Biosciences, USA) was used to analyze the cell cycle. Each test was conducted three times.

\section{Xenograft Model}

The animal experiment was conducted based on the Guide for the Care and Use of Laboratory Animals and in compliance with the guidelines of the Institute for Laboratory Animal Research at Guangzhou Medical University (Guangzhou, China). This research project has been reviewed and approved by Institutional Animal Care and Use Committee of Guangzhou 
Medical University. The PCa CT cells and CS-sh cells were collected and suspended in the medium mixed with Matrigel (1: 1; BD Biosciences, USA; Cat. No: $354,234)$. The cells $\left(5 \times 10^{6}\right.$ cells $\left./ 100 \mu \mathrm{L}\right)$ were injected into both sides of the flanks of 6 nude male mice subcutaneously (Left: CT cells; Right: CS-sh cells), which were 4-6 weeks old (Experimental Animal Center of Sun Yat-sen University, China). The mice's weight and the tumor size were measured every three days. The tumor volume was calculated as follow: $\mathrm{V}=$ length $\mathrm{x}$ width $^{2} \times 1 / 2$. The tumors were harvested after the mice were euthanized by $\mathrm{CO}_{2}$ suffocation.

\section{Metabolite Assay}

$10^{7}$ of PCa cells were collected and extracted by extraction solvent according to the protocol of the BioTree Company (Shanghai, China). The extracts were used for metabolic assay (ultra-performance liquidchromatography tandem mass spectrometry, UHPLCMS/MS). The UHPLC-MS/MS assay was conducted with a UHPLC system (1290, Agilent Technologies, USA). The levels of cell metabolites were quantified according to the standard curves. The results were reported by relative values. Detail informations of protocol were provided in Supplementary Material.

\section{MitoTracker Assay}

The PCa CT cells or CS-sh cells were seeded into the 6-well plates. MitoTracker ${ }^{\circledR}$ Red CMXRos probe (100 $\mathrm{nM}$; Invitrogen, USA; Cat. No: M7512) was added into the medium when cells reached $30-40 \%$ confluency and incubated for half an hour at $37{ }^{\circ} \mathrm{C}$. Then, Hoechst 33,342 staining solution was added into the medium for nuclear staining of living cells and incubated for 10 minutes at 37 ${ }^{\circ} \mathrm{C}$. The staining solution was substituted for PBS, and the cells were observed using a fluorescence microscope. For flow cytometry, the cells were resuspended in PBS and subjected to BD FACSVerse after the staining was completed.

\section{Seahorse Assay}

$\mathrm{PCa}$ CT cells or CS-sh cells were seeded in an XFe24 cell culture microplate. The mitochondrial function was determined by measuring the oxygen consumption rate of each cell line using the XFe24 Cell Mito Stress Test Kit (Agilent Technologies) according to the protocol of a previous study. ${ }^{15}$ The source of ATP was analyzed using The XF ATP Rate Assay (Agilent 103,592-100), according to the protocol of a previous study. ${ }^{16}$ The Seahorse assay was run in XFe24 Extracellular Flux Analyzer (Agilent Technologies). The results were analyzed using the Wave program 2.6.0 (Seahorse Bioscience).

\section{Statistical Analyses}

Continuous variables were shown as means \pm SD. All statistical analyses were performed by IBM SPSS Statistics 20 (SPSS Inc, USA) and GraphPad Prism 7 (GraphPad Software, USA) in the current study. The statistical significance of quantitative data was analyzed by Student's $t$-test or analysis of variance (ANOVA). The Kaplan-Meier method or Cox proportional hazards regression model were used for survival analysis. $P<0.05$ was regarded as statistically significant.

\section{Results}

\section{Overexpression of CS Protein and mRNA in Human PCa Tissues}

The expression levels of CS protein and mRNA in PCa and normal prostate tissues were examined by IHC, WB and RT-qPCR assay. As shown in Figure 1A-D, CS protein was mainly expressed in the PCa cells and its expression level in PCa tissues was higher than that in normal prostate tissues significantly (IRS: $\mathrm{PCa}=$ $5.63 \pm 3.22$ vs Normal $=2.67 \pm 2.07, P=0.031$; Figure 1E). High expression level of CS protein in $\mathrm{PCa}$ tissues was significantly associated with high Gleason score (IRS: GS $\geq 7=6.38 \pm 3.12$ vs GS $<7$ $=4.17 \pm 1.95, P=0.005$; Figure $1 \mathrm{~F}$ ). In addition, the protein and mRNA expression level of CS were detected in our collected prostate cancer and adjacent normal tissues using WB and RT-qPCR assay. The results showed that the CS protein and mRNA levels of PCa tissues were higher than those in normal tissues $(P=0.033$, Figure S1A; $P<0.001, \underline{\text { Figure S1B }})$. Also, the analysis results of TCGA-PRAD data showed that the CS mRNA expression of PCa tissues was higher than that in the adjacent normal tissue (Table 1).

\section{CS Overexpression is Associated with Aggressive Progression and Poor Prognosis of PCa Patients}

The associations between CS expression level and clinicalpathological parameters of PCa patients based in our TMA data and TCGA-PRAD database were shown in Table 1. 
A

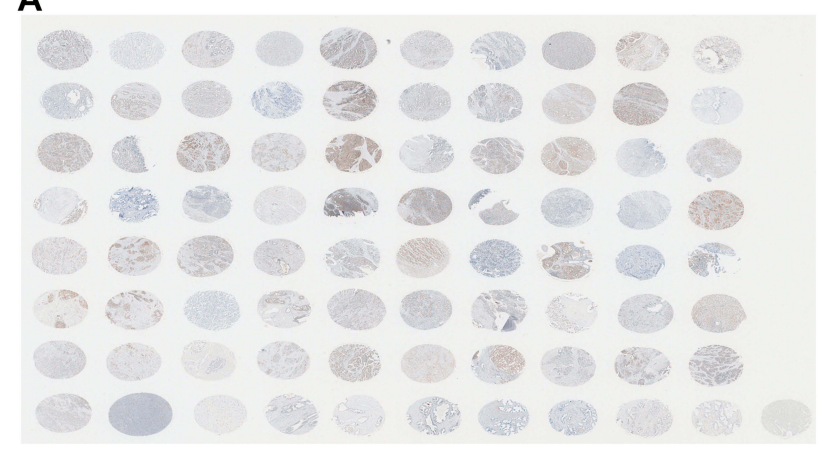

Overall View

C

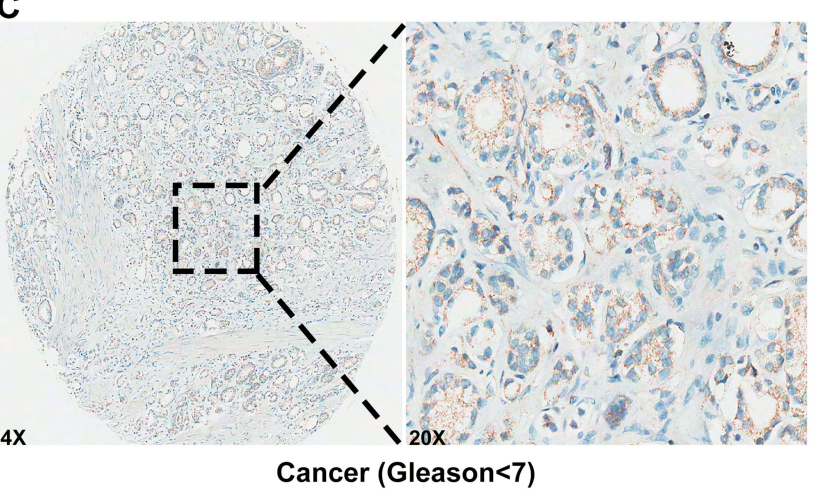

B

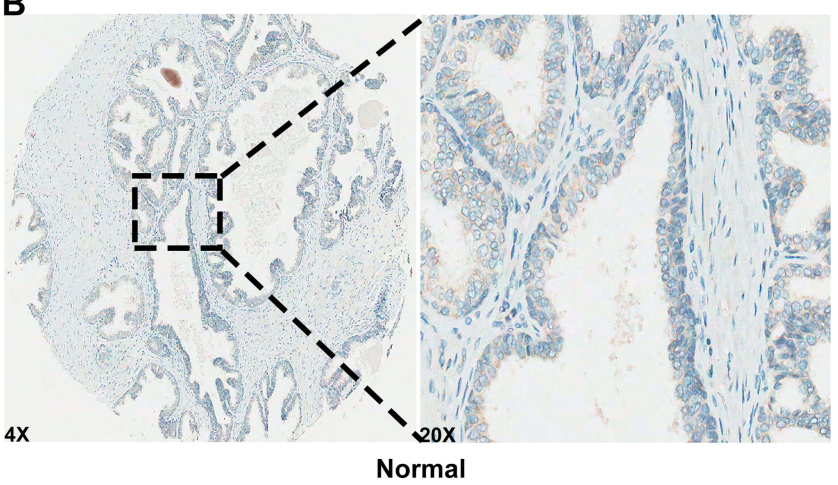

D

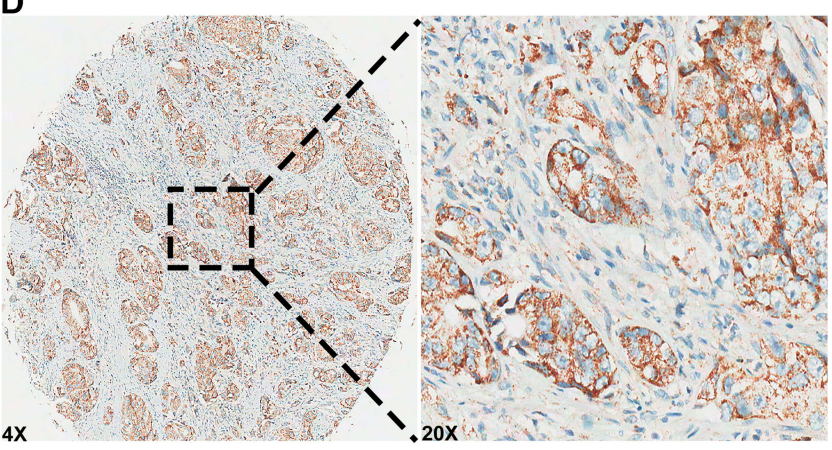

Cancer (Gleason $\geq 7$ )

Number at risk by time

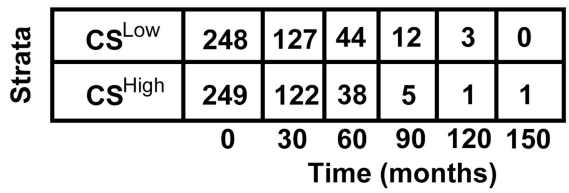

H

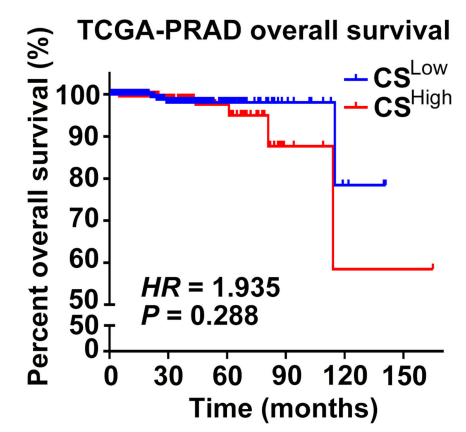

(months)

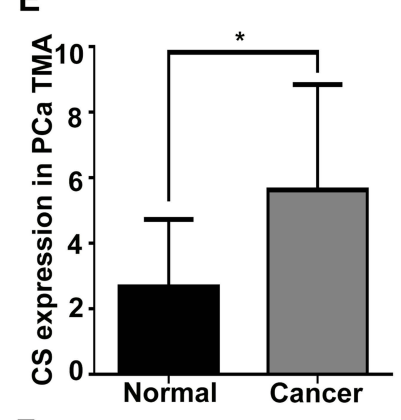

$\mathbf{F}$

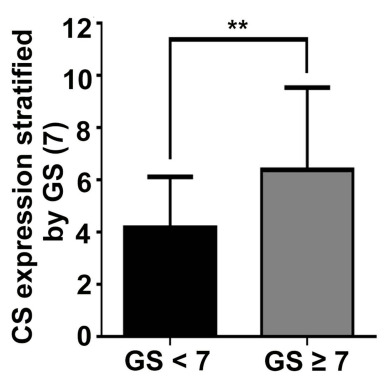

G

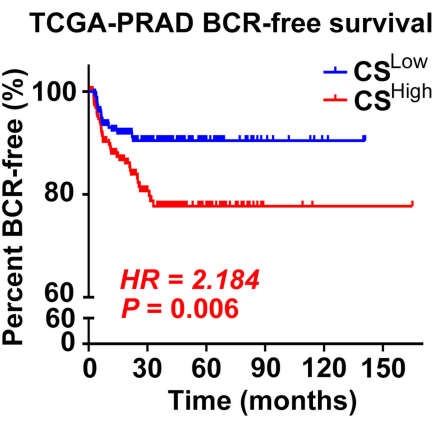

\begin{tabular}{|c|c|c|c|c|c|c|}
\hline \multicolumn{7}{|c|}{ Number at risk by time } \\
\hline CS $^{\text {Low }}$ & 219 & 96 & 31 & 10 & 3 & 0 \\
\hline cs $^{\text {High }}$ & 204 & 85 & 25 & 3 & 1 & 1 \\
\hline
\end{tabular}

Figure I Overexpression of CS protein in human PCa tissues, and its prognostic value. (A) Overall view of CS immunostainings in 80 prostate samples of TMA which consists of $7 \mathrm{I}$ cases of prostate adenocarcinoma, 2 prostate leiomyosarcoma, I prostate hyperplasia and 6 normal prostate tissues. (B-D) Immunostainings of CS protein in normal prostate tissues, PCa tissues with low Gleason score $(G S<7)$, and high Gleason score (GS $\geq 7$ ), respectively. (E) The histogram showed the IHC scores of CS expression in normal prostate and PCa tissues. (F) IHC scores of CS expression in PCa tissues with GS $<7$ and GS $\geq 7$. (G-H) The Kaplan-Meier curves of BCR-free survival and overall survival between CS low and high expression groups of TCGA-PRAD patients stratified by the median of CS expression level. The risk tables were provided below the curves. $* P<0.05$, $* * P<0.01$.

Abbreviations: CS, citrate synthesis; PCa, prostate cancer; TMA, tissue microarray; IHC, immunohistochemistry; TCGA-PRAD, The Cancer Genome Atlas-Prostate Adenocarcinoma; $B C R$, biochemical recurrence; $H R$, hazard ratio. 
Table I Association of CS with Clinicopathological Characteristics of PCa in TMA and TCGA-PRAD Dataset

\begin{tabular}{|c|c|c|c|c|c|c|}
\hline \multirow[t]{2}{*}{ Clinical Features } & \multicolumn{3}{|c|}{ CS Expression in TMA } & \multicolumn{3}{|c|}{ CS Expression in TCGA-PRAD Dataset } \\
\hline & $\mathbf{n}$ & Means \pm SD & $P$ & $\mathbf{n}$ & Means \pm SD & $\mathbf{P}$ \\
\hline $\begin{array}{l}\text { CS expression } \\
\text { Normal } \\
\text { Cancer }\end{array}$ & $\begin{array}{l}6 \\
67 *\end{array}$ & $\begin{array}{l}2.67 \pm 2.07 \\
5.63 \pm 3.22\end{array}$ & 0.031 & $\begin{array}{l}52 \\
498\end{array}$ & $\begin{array}{l}2944 \pm 512 \\
3529 \pm 787\end{array}$ & $<0.001$ \\
\hline $\begin{array}{l}\text { Age } \\
\qquad 65 \text { years } \\
\quad \geq 65 \text { years }\end{array}$ & $\begin{array}{l}22 \\
45\end{array}$ & $\begin{array}{l}6.14 \pm 2.90 \\
5.38 \pm 3.37\end{array}$ & 0.369 & $\begin{array}{l}331 \\
166\end{array}$ & $\begin{array}{l}3496 \pm 786 \\
3601 \pm 782\end{array}$ & 0.160 \\
\hline $\begin{array}{l}\text { Gleason score }^{\#} \\
\quad<7 \\
\geq 7\end{array}$ & $\begin{array}{l}12 \\
50\end{array}$ & $\begin{array}{l}4.17 \pm 1.95 \\
6.38 \pm 3.12\end{array}$ & 0.005 & $\begin{array}{l}44 \\
453\end{array}$ & $\begin{array}{l}3268 \pm 695 \\
3556 \pm 790\end{array}$ & 0.020 \\
\hline $\begin{array}{l}\text { Pathological stage } \\
\quad<\mathrm{T} 3 \mathrm{~A} \\
\geq \mathrm{T} 3 \mathrm{~A}\end{array}$ & $\begin{array}{l}39 \\
28\end{array}$ & $\begin{array}{l}5.15 \pm 3.29 \\
6.29 \pm 3.05\end{array}$ & 0.157 & $\begin{array}{l}186 \\
304\end{array}$ & $\begin{array}{l}3342 \pm 618 \\
3652 \pm 852\end{array}$ & $<0.001$ \\
\hline $\begin{array}{l}\text { Metastasis } \\
\text { No } \\
\text { Yes }\end{array}$ & $\begin{array}{l}42 \\
25\end{array}$ & $\begin{array}{l}5.17 \pm 2.95 \\
6.40 \pm 3.55\end{array}$ & 0.130 & $\begin{array}{l}416 \\
82\end{array}$ & $\begin{array}{l}3510 \pm 786 \\
3622 \pm 787\end{array}$ & 0.242 \\
\hline $\begin{array}{l}\text { Overall survival } \\
\text { Alive } \\
\text { Die }\end{array}$ & - & - & - & $\begin{array}{l}487 \\
10\end{array}$ & $\begin{array}{l}3526 \pm 785 \\
3789 \pm 816\end{array}$ & 0.295 \\
\hline $\begin{array}{l}\text { PSA failure } \\
\text { Negative } \\
\text { Positive }\end{array}$ & $\begin{array}{l}- \\
-\end{array}$ & - & - & $\begin{array}{l}370 \\
59\end{array}$ & $\begin{array}{l}3464 \pm 760 \\
3847 \pm 738\end{array}$ & $<0.001$ \\
\hline
\end{tabular}

Notes: -Lack of relative information of patients in the cohort; ${ }^{*} 4$ cases of prostate adenocarcinoma tissue dropped off during the immunohistochemistry experiment; ${ }^{*} 5$ cases of prostate adenocarcinoma tissue had no Gleason score.

Abbreviations: CS, citrate synthesis; PCa, prostate cancer; TMA, tissue microarray; TCGA-PRAD, The Cancer Genome Atlas-Prostate Adenocarcinoma; SD, standard deviation; PSA, prostate-specific antigen.

The expression level of CS in PCa tissues was significantly associated with high Gleason score (for IHC data: $P=0.005$, for TCGA-PRAD data: $P=0.020$, Table S1), advanced pathological stage (for TCGA-PRAD data: $P<$ $0.001)$ and positive biochemical recurrence $(\mathrm{BCR}$; for TCGA-PRAD data: $P<0.001)$.

The survival analysis was performed in the TCGAPRAD database in order to assess the prognostic value of CS expression in patients with PCa. The median expression level of CS in PCa tissues was used as a demarcation point to divide the patients into high CS expression group and low CS expression group. As shown in Figure 1G, patients with high CS expression had shorter BCR-free survival than patients with low CS expression $(P=0.006$; hazard ratio $=2.184$, 95\% confidence interval: 1.273 to 3.745$)$. However, no significant difference was observed $(P=0.288$; Figure $1 \mathrm{H}$; hazard ratio $=1.935,95 \%$ confidence interval: 0.554 to 6.751$)$.

\section{CS Knockdown Inhibits PCa Cell Proliferation, Cell Colony Formation, Cell Migration, Cell Invasion and Cell Cycle in vitro}

In a previous study, CS mRNA expression level was found to upregulate in the CTCs of CRPC (Castration Resistant Prostate Cancer) patients. ${ }^{12}$ Therefore, to explore the role of $\mathrm{CS}$ in $\mathrm{PCa}$ in vitro, we established the CS knockdown stable PCa cell lines DU145 and PC3, using a lentivirus vector containing shRNA of CS (CT, CS-sh). The knockdown efficiency was detected by Western blot and RT-qPCR assay (Figure 2A and Figure S2). CCK-8 assay indicated that the reduced expression of CS protein suppressed the cell proliferation of both DU145 cells and PC3 cells (for DU145 96h: $P=0.004$, for PC3 96h: $P<0.001$; Figure $2 \mathrm{~B}$ ). The colony formation assay also demonstrated that the colony formation abilities of CS knockdown $\mathrm{PCa}$ cells were diminished compared with those of the $\mathrm{CT}$ group 

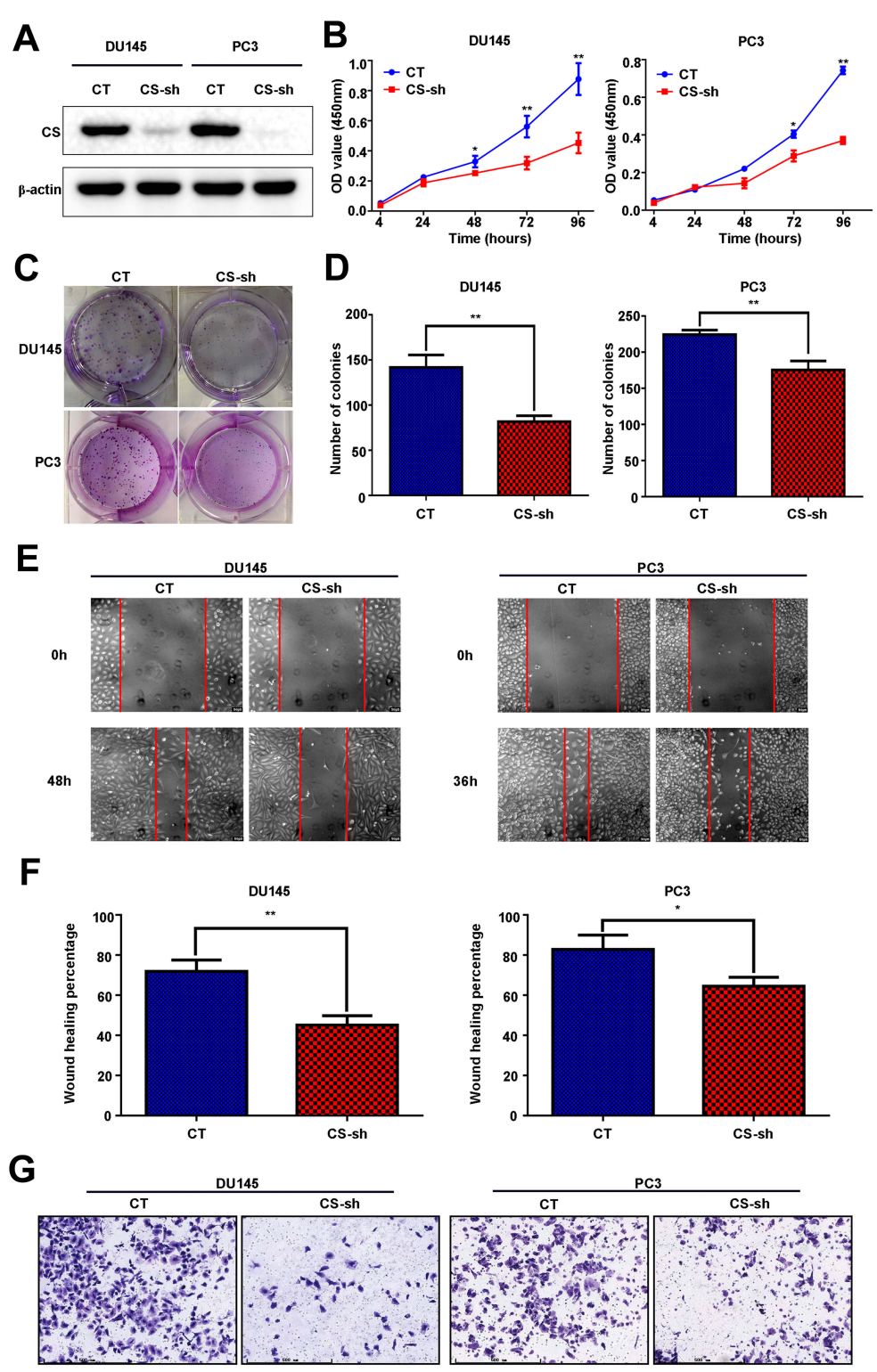

$\mathbf{H}$
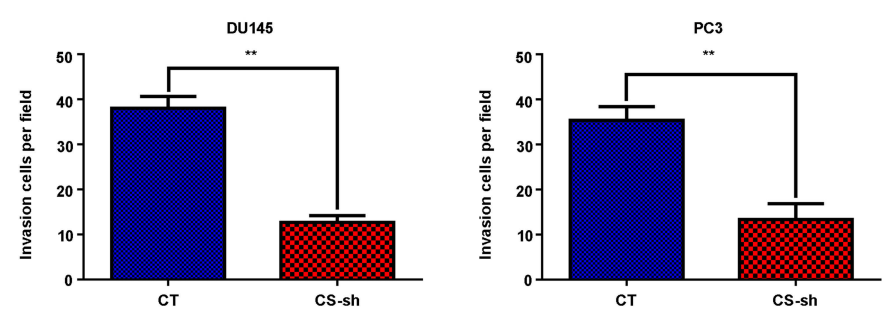

Figure 2 Decreased expression of CS inhibited cell proliferation, cell invasion, and migration of PCa cells in vitro. (A) Expression levels of CS protein in DUI45 and PC3 cell lines, which were transfected with CS-shRNA and negative control vector and verified through Western blot assay. (B-D) The proliferation was detected through growth curves and colony formation in DUI45 and PC3 cells with CS knockdown and negative control (CT) vector. (E-F) The migration was examined by wound healing percentage in CT and CS-sh group cells of DUI45 and PC3. The Red lines refer to the edge of the cells. (G-H) The invasion was analyzed using the Transwell experiment in CT and CS-sh group cells of DUI45 and PC3. The matrigel was added to the upper chamber. $* P<0.05, * * P<0.01$.

Abbreviations: CS, citrate synthesis; PCa, prostate cancer; sh, short hairpin; CT, control.

significantly (for DU145: $P=0.003$; for PC3: $P=0.004$; Figure $2 \mathrm{C}$ and $\mathrm{D})$. Both the cell migration and invasion assays indicated that the reduced expression of CS protein suppressed the migration and invasion of DU145 and PC3 cells (for DU145: $P_{\text {Migration }}=0.001, P_{\text {Invasion }}<0.001$; for PC3: $P_{\text {Migration }}=0.020, P_{\text {Invasion }}=0.001 ;$ Figure $\left.2 \mathrm{E}-\mathrm{H}\right)$. 

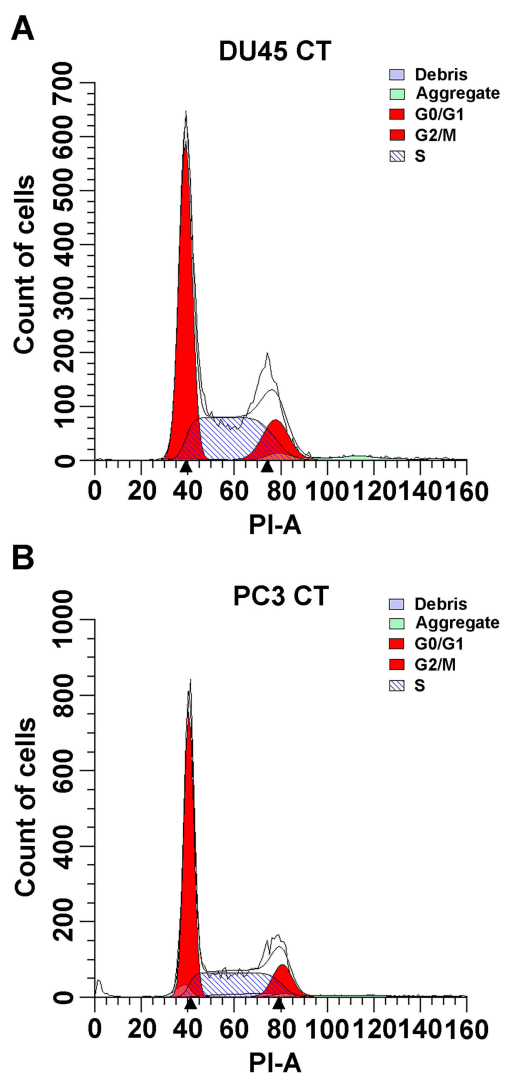
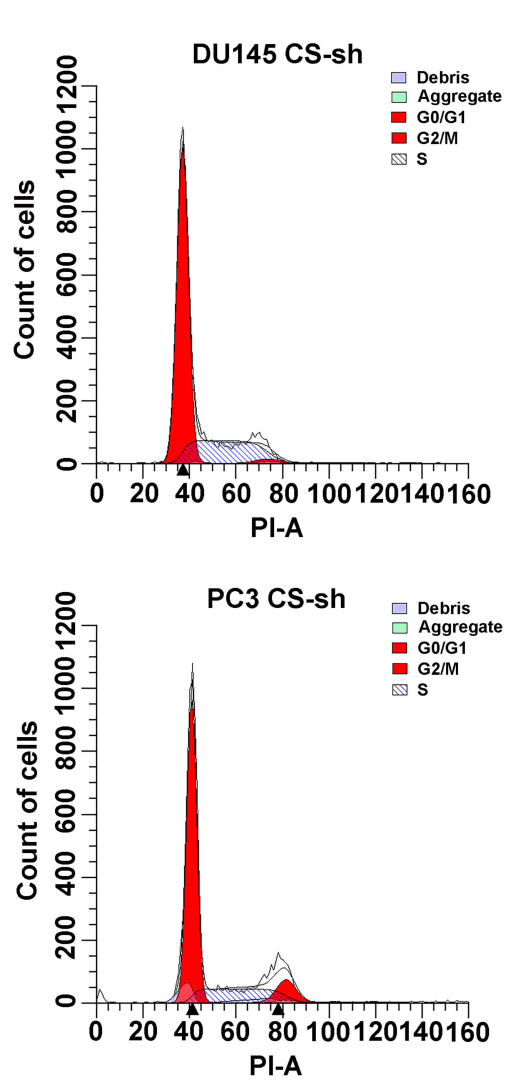

C

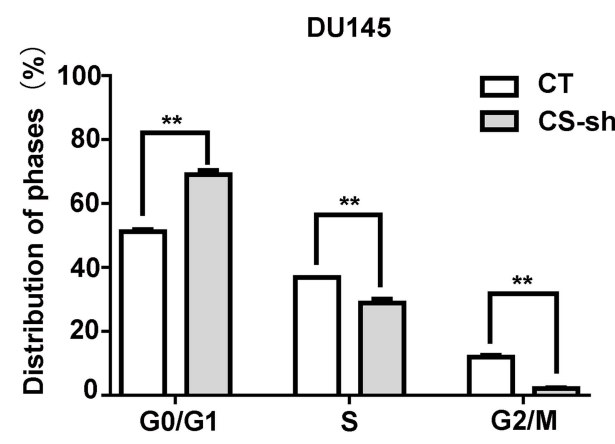

D

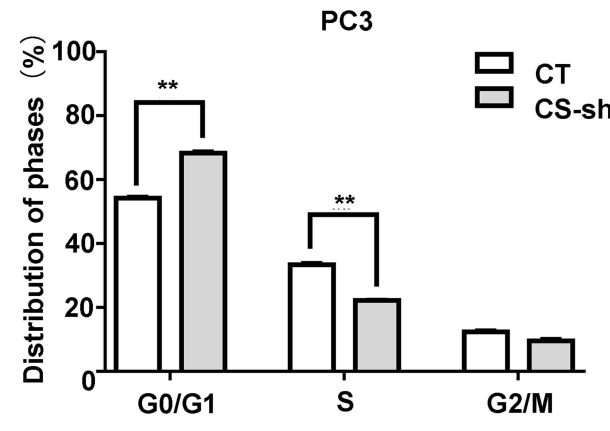

Figure 3 Decreased expression of CS inhibited cell cycle progression in vitro. (A and B) Cell cycle assay detected by flow cytometer of DUI45 and PC3 cells with CS knockdown or CT vector. The $y$-axis showed the count of effective cells, and the x-axis showed the DNA content. The red area on the left referred to the cells in the G0/ GI phase, the diagonal region in the middle area referred to the cells in the S phase, and the red area on the right referred to the cells in the G2/M phase. Debris referred to cell debris. Aggregate referred to cell aggregation. (C and D) The histogram demonstrated the quantitative analysis of the cell cycle in DUI45 and PC3 cells with CS knockdown or $\mathrm{CT}$ vector. $* * \mathrm{P}<0.01$.

Abbreviations: CS, citrate synthesis; $\mathrm{CT}$, control.

Moreover, CS downregulation in DU145 and PC3 cell lines induced an increase in the percentage of G0/G1 phase cells and a decrease in the percentage of $\mathrm{S}$ phase (for DU145: $\mathrm{P}<0.001$, for $\mathrm{PC} 3: \mathrm{P}<0.001$; Figure $3 \mathrm{~A}-\mathrm{D}$ ).

\section{CS Knockdown Inhibits Tumor Growth in $\mathrm{PCa}$ Xenograft Model in vivo}

To study the role of CS in the growth of $\mathrm{PCa}$ in vivo, we established a model of xenograft nude mice through injecting PC3 CT and PC3 CS knockdown cells subcutaneously into male nude mice. The tumor growth velocity of the CS knockdown group was slower compared with that of the CT group $(P<0.001$, Figure $4 C)$. The tumors in the CS knockdown group also had a smaller size and lighter weight than those in the CT group over a 5 weeks' feeding (for size: $P<0.001$, for weight: $P=0.002$; Figure 4A and B). The protein expression level of CS in CS-sh group was significantly lower than that in CT group (Figure 4D).

\section{CS Knockdown Exerts the Inhibitory} Effects on Cell Lipid Metabolism and Mitochondrion Function of PCa Cells

UHPLC-MS/MS analysis was performed to detect the molecular basis for the oncogenic function of $\mathrm{CS}$ in $\mathrm{PCa}$ cells. The volcano plots of DU145 and PC3 cells showed the metabolites with differential levels between the CS knockdown group and the $\mathrm{CT}$ group (Figure 5A). A clustering heatmap to illustrated significantly expressed metabolites was shown in Figure 5B. As a result, we found that TCA metabolites like citrate and cis-Aconitate levels were lessened in DU145 and PC3 cells with the CS knockdown. In addition, glyceraldehyde 3-phosphate (G3P) and glyceryl triphosphate levels (TG(14:1(9Z)/16:0/14:1(9Z)) and $\mathrm{TG}(18: 2(9 \mathrm{Z}, 12 \mathrm{Z}) / 22: 6(4 \mathrm{Z}, 7 \mathrm{Z}, 10 \mathrm{Z}, 13 \mathrm{Z}, 16 \mathrm{Z}, 19 \mathrm{Z}) / 22: 6$ (4Z,7Z,10Z,13Z,16Z,19Z))) in the CS knockdown group were lower than those of CT group (for DU145: $P_{\mathrm{G} 3 \mathrm{P}}=$ $0.040, P_{\mathrm{TG} 14}=0.044, P_{\mathrm{TG} 18}=0.009$; for PC3: $P_{\mathrm{G} 3 \mathrm{P}}=$ 
A

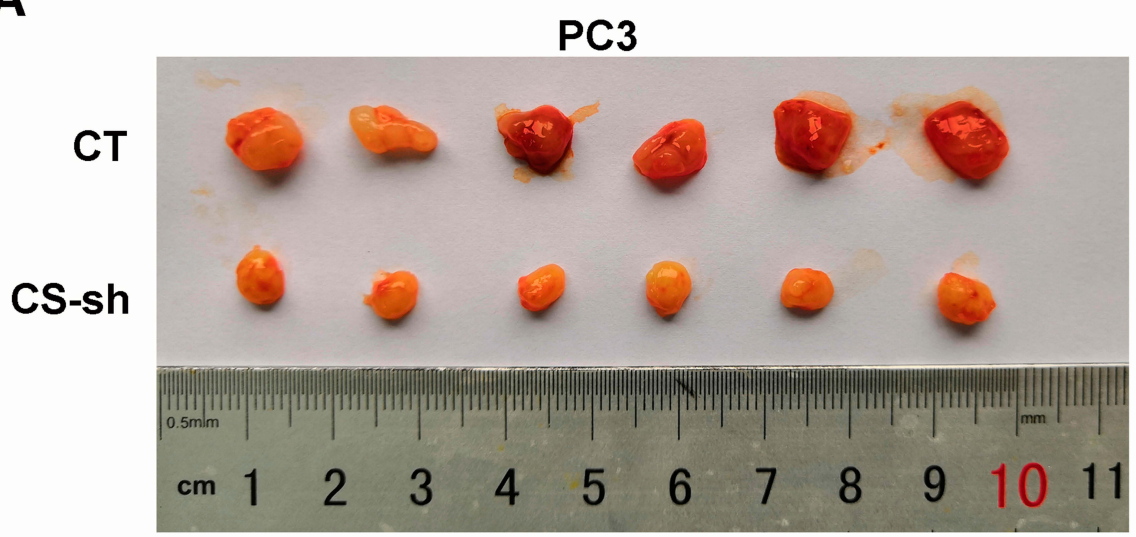

B

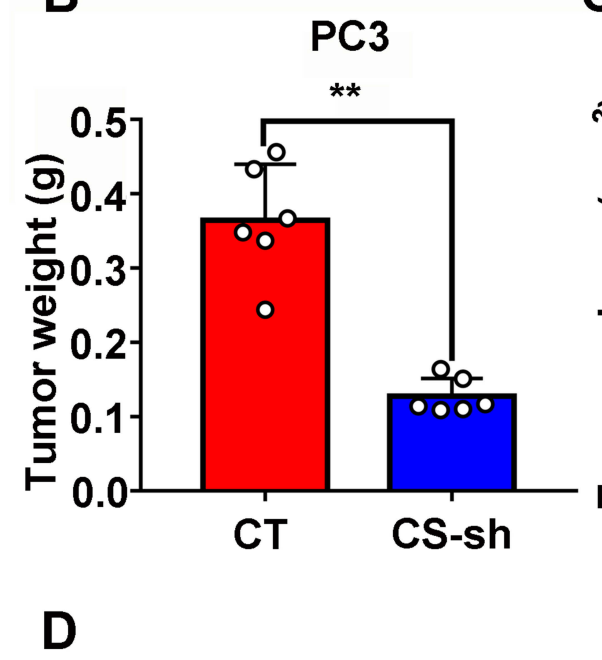

C PC3

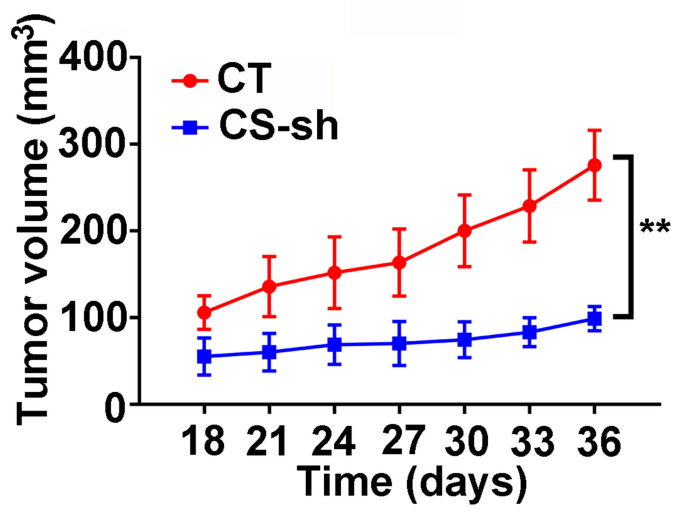

PC3

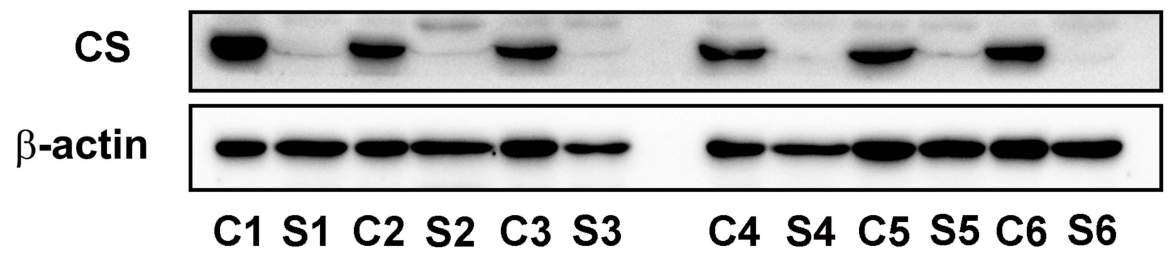

Figure 4 Downregulated expression of CS inhibits PC3 tumor growth in a xenograft model in vivo. (A) Represent photos of tumors from the xenograft model subcutaneously implanted with PC3 cells stably CS knockdown or negative CT. (B and C) The weight and growth curves of tumor of CS knockdown tumors and CT tumors. (D) Western blot assay of CS protein in xenograft tumors derived from CT cells and CS-sh cells. $* * P<0.01$.

Abbreviations: CS, citrate synthesis; CT, control; CI-6, control I-6; SI-6, CS-sh I-6.

0.001, $P_{\mathrm{TG} 14}=0.032, P_{\mathrm{TG} 18}=0.015$; Figure 5C). We also performed functional enrichment analysis on the differential expression of CS in the transcriptome TCGA-PRAD database. Gene Set Enrichment Analysis (GSEA) of candidate lipid metabolism pathways showed significant enrichment for "REACTOME_REGULATION_OF_ LIPID_METABOLISM_BY_PPARALPHA” signaling in
CS high expression patients compared to CS low expression patients ( $\underline{\text { Figure } \mathrm{S} 3} ; P=0.011, \mathrm{FDR}=0.011$ ).

As the mitochondrion is one of the reaction sites of the lipid metabolites described above, we further examined the impact of CS protein on the mitochondrial function of PCa cells. The MitoTracker assay was performed to detect the changes in the mitochondrial 
A

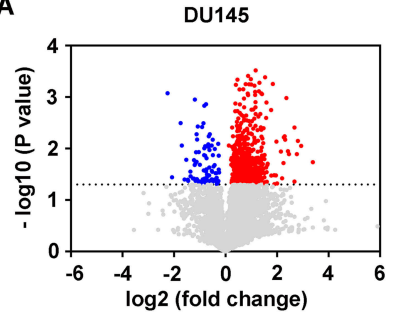

PC3

Down-regulated No significant change -Up-regulated

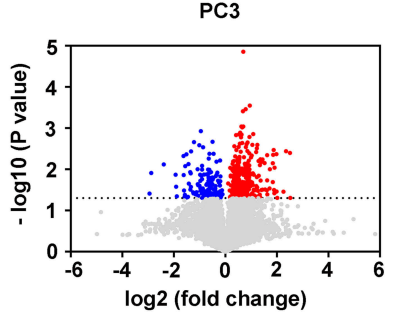

-Down-regulated

No significant change

-Up-regulated

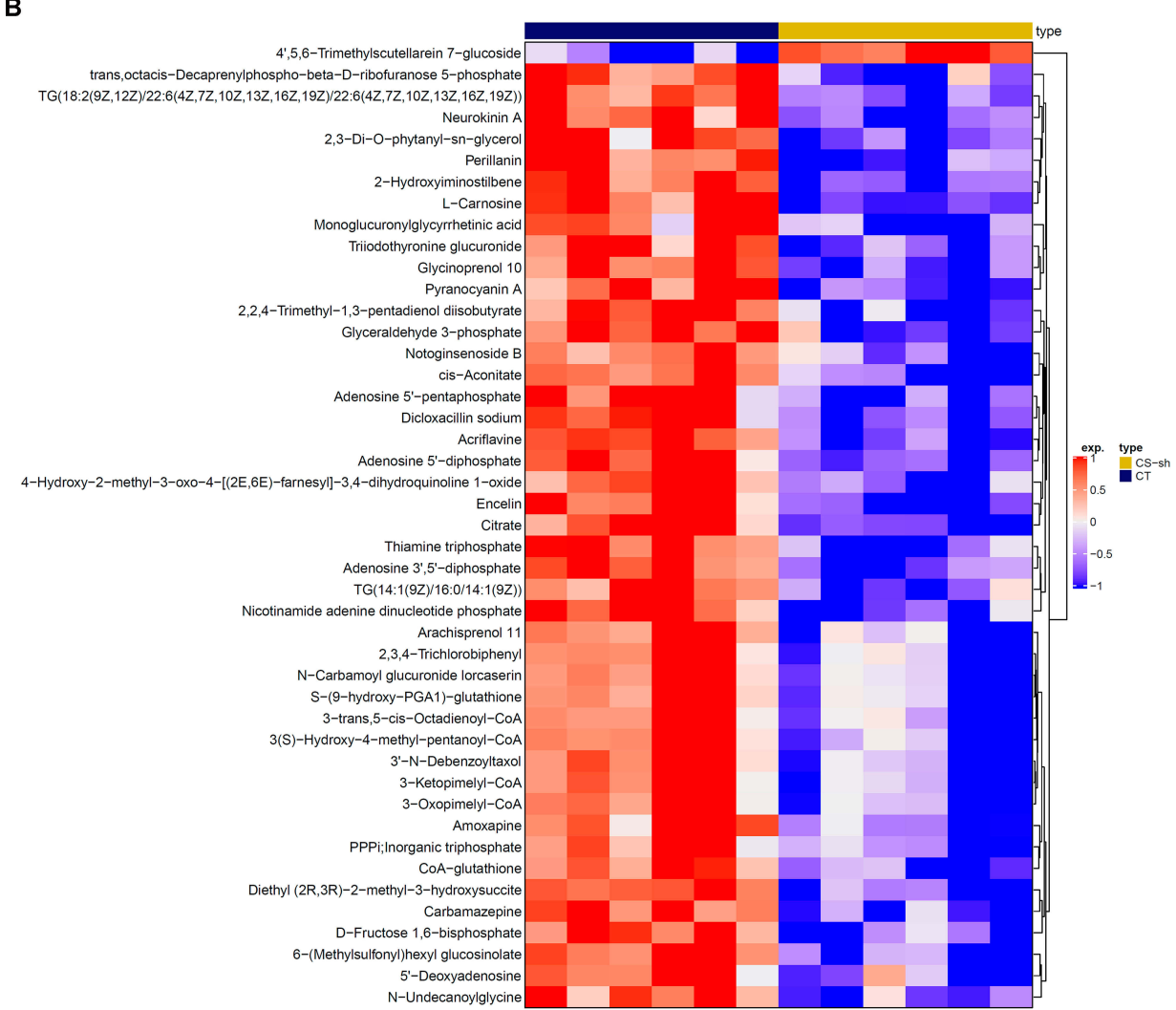

C

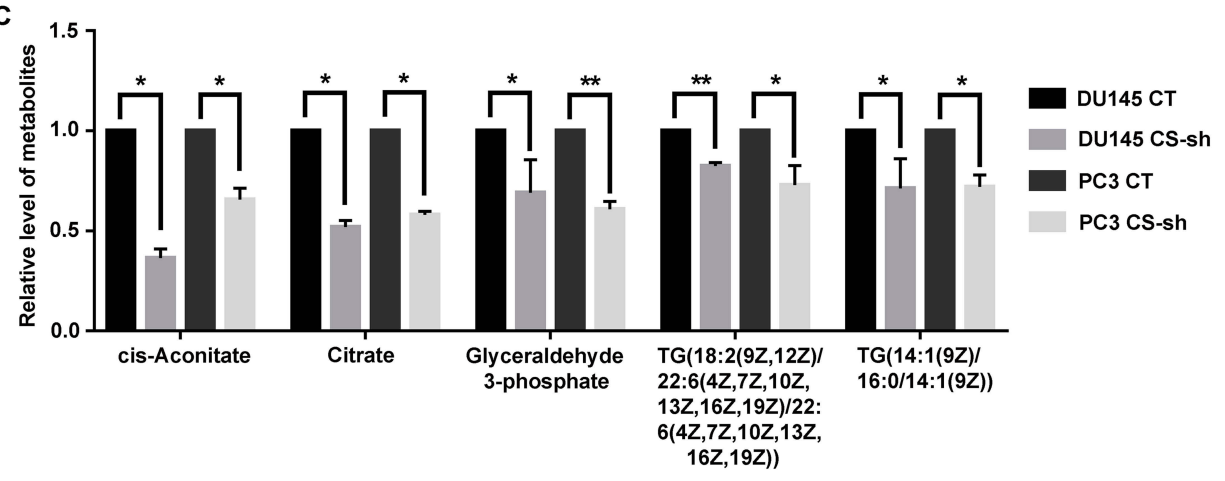

Figure 5 CS knockdown exerts the inhibitory effects on inhibits cell lipid metabolism of PCa cells. (A) The volcano plots showed genes differentially expressed between DUI45 and PC3 cells with CS knockdown group and the CT group (P-value < 0.05). (B) The clustering heatmap of significantly expressed metabolites in CS knockdown cells compared to those in CT cells. (C) The relative quantitative histogram showed that the levels of cis-Aconitate, citrate, glyceraldehyde 3-phosphate, TG(I8:2(9Z,I2Z)/ 22:6(4Z,7Z, I0Z, I3Z, I6Z, I9Z)/22:6(4Z,7Z, I0Z,I3Z, I6Z, I9Z)) and TG(I4:I(9Z)/I6:0/I4:I(9Z)) in the CS-knockdown cells and CT cells. $* P<0.05$, $* * P<0.01$. Abbreviations: CS, citrate synthesis; $\mathrm{PCa}$, prostate cancer; $\mathrm{CT}$, control; TG, triglyceride.

function of $\mathrm{PCa}$ cells in the $\mathrm{CS}$ knockdown and $\mathrm{CT}$ groups. As shown in Figure 6A and B, the cell fluorescence under MitoTracker staining was obviously decreased in the CS knockdown cells compared with that of the CT group, which was further confirmed by MitoTracker flow cytometry (for DU145: $P<0.001$, for 
A
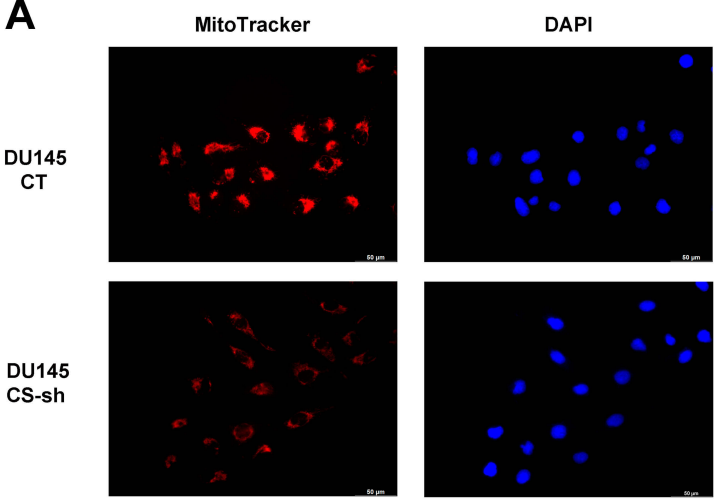

B
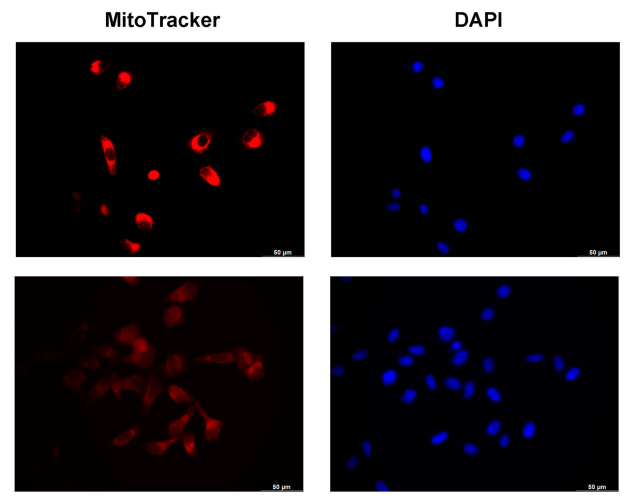

DU145
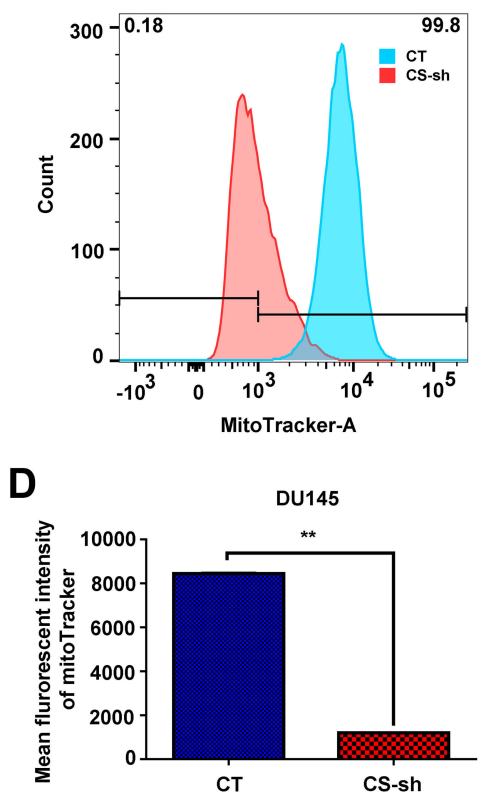
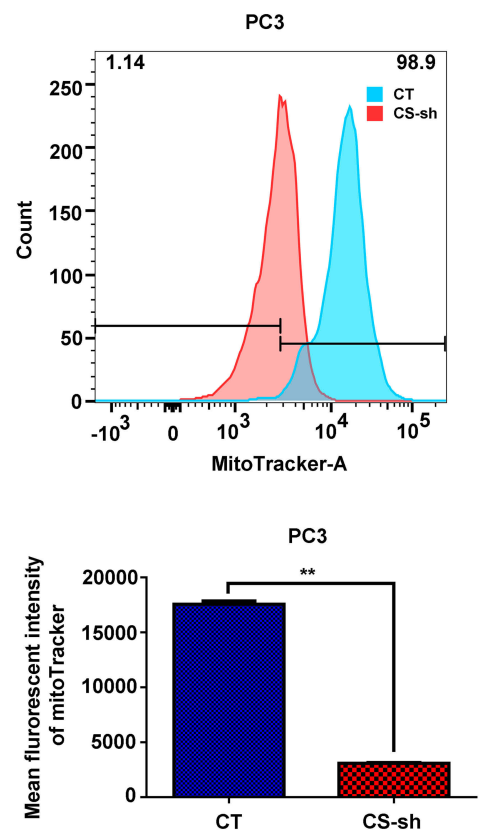

Figure 6 Downregulated expression of CS inhibits the mitochondrial function of PCa cells. (A and B) The mitochondrial fluorescence of MitoTracker assay under a fluorescent microscope in DUI45 and PC3 cells with CS knockdown and CT vector. The red area indicated mitochondria. The blue area indicated nuclear. (C and D) The MitoTracker flow cytometry of DUI45 and PC3 cells with CS knockdown and CT vector. The red area referred CS-sh group. The blue area referred CT group. The histogram demonstrated the quantitative analysis of the mitochondrial fluorescence. $* * P<0.01$.

Abbreviations: CS, citrate synthesis; PCa, prostate cancer; CT, control.

PC3: $P<0.001$; Figure 6C and D). We next examined the mitochondrial function by testing the oxygen consumption rate (OCR) of DU145 and PC3 cells with CS knockdown and negative $\mathrm{CT}$ vector, using seahorse assay (Figure 7A and B). We found that CS downregulation could significantly inhibit both baseline 
A

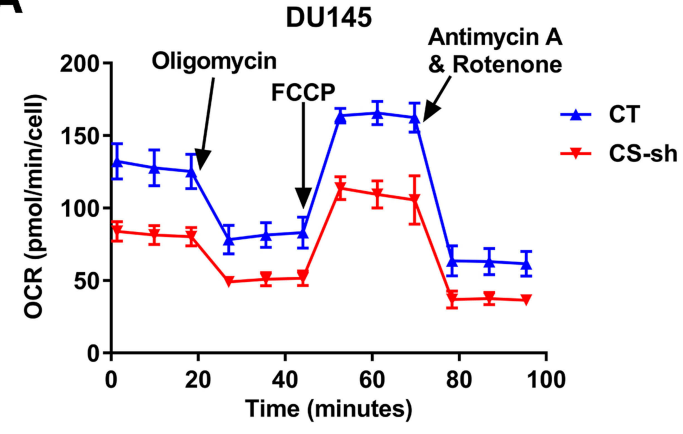

C

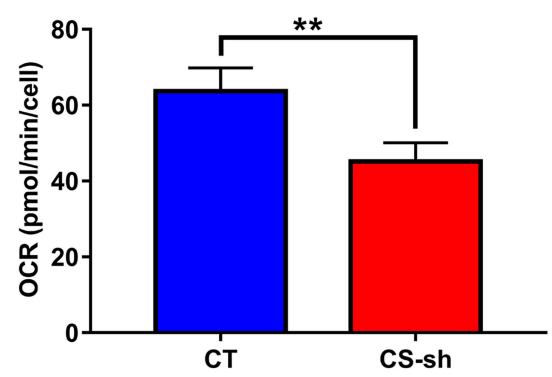

$\mathbf{E}$

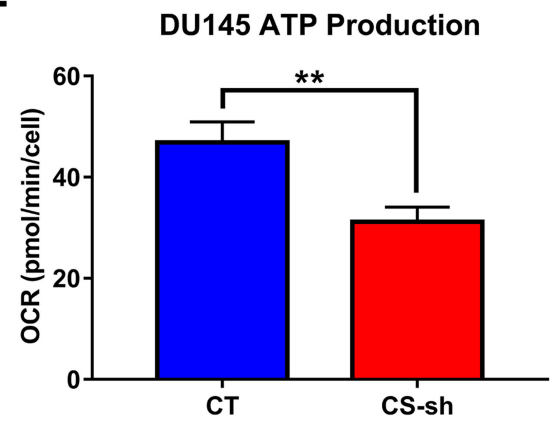

G

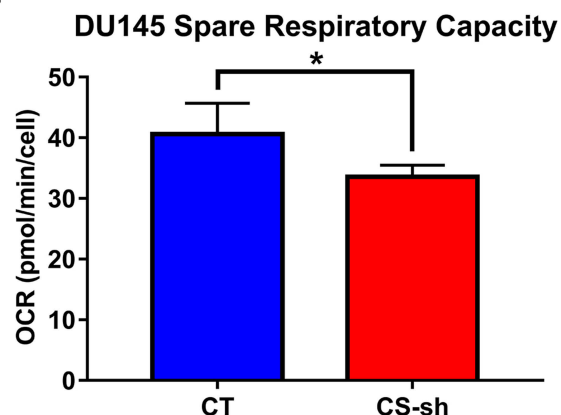

B

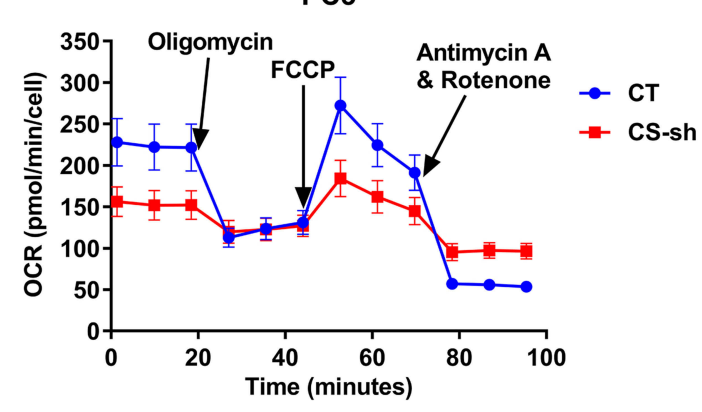

D

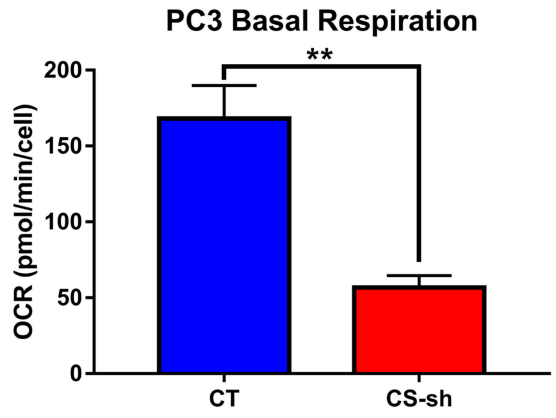

F

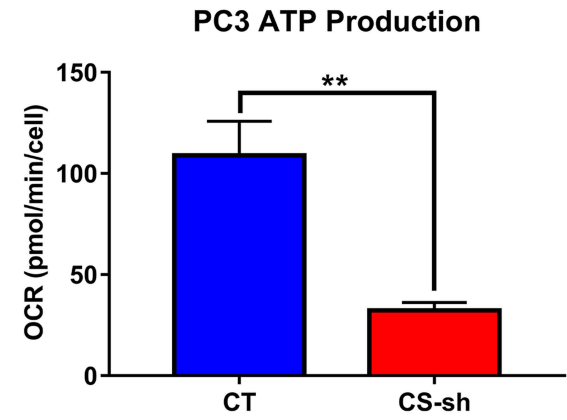

H

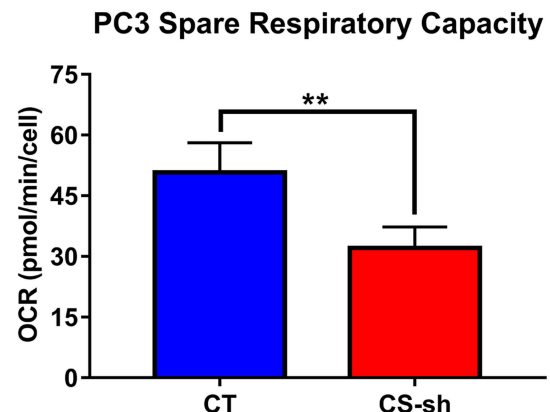

Figure 7 Downexpression of CS inhibited mitochondrial respiration and reduced mitochondrial-ATP production. (A and B) Oxygen consumption rate (OCR) in DUI45 and PC3 cells with CS knockdown and CT vector. The OCR was divided into three parts and analyzed by Seahorse assay, including baseline respiration, spare respiratory capacity and ATP production. As long as one or more of these parts were suppressed, the mitochondrial function is impaired. (C-H) Baseline respiration (C and D), ATP production $(\mathbf{E}$ and $\mathbf{F})$ and spare respiratory capacity $(\mathbf{G}$ and $\mathbf{H})$ were significantly inhibited in CS-sh cells compared with those in $\mathrm{CT}$ cells. $* \mathrm{P}<0.05$, $* * \mathrm{P}<0.0 \mathrm{I}$.

Abbreviations: CS, citrate Synthesis; ATP, adenosine triphosphate; CT, control; FCCP, carbonyl cyanide 4-(trifluoromethoxy)phenylhydrazone). 
respiration, ATP production and spare respiratory capacity compared with the control group (Figure $7 \mathrm{C}-\mathrm{H}$ ).

\section{Discussion}

An increasing number of scientific researches has paid attention to identifying the diagnostic and prognostic biomarkers of PCa. In this study, we firstly verified the overexpression of CS protein and mRNA in PCa tissues compared to the normal prostate tissues. High CS expression was found to be significantly associated with various aggressive clinical-pathological features of patients with $\mathrm{PCa}$, such as high Gleason score, advanced pathological stage, and positive biochemical recurrence. CS expression might be one of the prognostic markers for BCR-free survival of patients with PCa. Functionally, the reduced expression of CS suppressed PCa cell proliferation, colony formation, migration, invasion and cell cycle in vitro. And decreased expression of CS inhibited tumor growth in vivo. In addition, CS downregulation exerts potential inhibitory effects on the lipid metabolism and mitochondrial function of PCa cells.

Growing evidence showed that metabolic changes were possible to play an important role in the development, progression, and drugs resistance of $\mathrm{PCa} .{ }^{17-21}$ Among them, the changes of TCA cycle enzymes have been observed in multiple human cancers. ${ }^{22}$ Mitochondria as the main reaction site of TCA cycle, its dysfunction caused by abnormal metabolic enzymes and metabolites is a driving factor for cancer and can be used as a "second hit" in the metabolic transformation of cancer. ${ }^{23,24}$ As a limiting velocity enzyme that catalyzes the first step of the TCA cycle, the aberrant expression of CS has been revealed to be related with various malignancies, which included ovarian cancer, pancreatic cancer, cervical cancer, and renal cancer, ${ }^{8,9,10,25}$ in line with which, we herein observed the strong positive immunostaining and the upregulated expression level of CS protein in PCa tissues compared to the normal prostate tissues. According to the results of TCGA-PRAD data and our TMA cohort, we determined the positive correlation of CS overexpression with $\mathrm{PCa}$ advanced progression and poor prognosis.

Lin et al reported that CS knockdown induced epithelial-mesenchymal transformation of cervical cancer cells, and accelerated metastasis, proliferation, and tumor growth. ${ }^{10}$ On the contrary, Chen et al showed that the decreased expression of CS led to the inhibition of cell proliferation, cell migration, and invasion of ovarian cancer cells. ${ }^{8}$ To determine the biological functions of CS protein in PCa. In this study, we established the CS knockdown DU145 and PC3 cell lines using the specific shRNA to CS. Through a series of functional experiments, our data demonstrated that the reduced expression of CS protein significantly decreased the malignancy of $\mathrm{PCa}$ cells, including the inhibition of cell proliferation, colony formation, migration, and invasion. Especially, CS downregulation might arrest the cell cycle process from $\mathrm{G} 0 / \mathrm{G} 1$ to S phase. Consistently, the CS downregulation also exerted a function suppressing tumor growth and progression in mice.

Mycielska et al reported that the providing of exogenous citrate reinforced endocytosis, lateral movement, and suppressed adhesion of PCa cells. The enhancement of cell transfer behavior is related to the conversion of citrate to fatty acids. ${ }^{11}$ In this study, we demonstrated that the levels of citrate and cis-aconitic acid in the CS knockdown cells of PCa were significantly less than those in the control cells. Our untargeted metabolomics results showed that the productions of G3P and triglycerides were decreased in our CS knockdown cell lines. In a previous study, ${ }^{26}$ a part of the excess citrate can transfer to the cytosol and degrade to acetyl-CoA in the cellular higher energy level. Thereafter, acetyl-CoA can be used in the fatty acid and cholesterol synthesis. Citrate also has a positive regulatory effect on the enzymes of lipo-genesis. ${ }^{26} \mathrm{Mao}^{27}$ and Barber ${ }^{28}$ reported that the enhanced activity of ACC promoted the synthesis and deposition of cellular triglycerides. It suggested that citrate may interfere with lipid metabolism through ACC. In addition, glyceraldehyde triphosphate is a member of the pentose phosphate pathway. Pentose phosphate pathway could produce a large amount of NADPH and participate in the synthesis of fatty acids and sterols. These findings suggested that citrate may also affect lipid metabolism through influence glyceraldehyde triphosphate. We also performed functional enrichment analysis on the differential expression of CS in the transcriptome TCGA-PRAD database. Gene Set Enrichment Analysis showed significant enrichment for lipid metabolism signaling in CS high expression patients compared to CS low expression patients. Therefore, CS might regulate the level of citrate and affect the synthesis of cellular lipids, which were involved in a lot of cellular processes critical for cell transformation, tumor development, and disease progression. ${ }^{29}$

Recent studies have reported that cancer cells may tend to synthesize de novo lipids and increase the rate of intracellular lipid synthesis. ${ }^{30,31}$ Consistently, our data 
imply that PCa cells may increase the production of citrate through CS and promote the synthesis of intracellular lipids, which may promote the proliferation and metastatic potentials of cells. Moreover, it has been reported that cell mitochondrial dysfunction and altered lipid homeostasis may play a role in cancer progression. ${ }^{32}$ To investigate the involvement of CS in mitochondrial function, we performed the MitoTracker and Seahorse experiment based on the $\mathrm{CS}$ knockdown and control $\mathrm{PCa}$ cells. The decreased expression of CS protein also suppress the mitochondrial OCR of $\mathrm{PCa}$ cells, which might decrease the synthesis of lipids.

However, there are still several limitations to this study. In addition to the loss-of-function experiments, the gain-of-function experiments are also needed to verify the oncogenic role of CS in PCa. In our preliminary studies, the CS overexpression PCa cell lines were not successfully established due to the technical problems which we are trying to resolve.

\section{Conclusion}

In conclusion, these findings suggest that CS upregulation is associated with the aggressive progression and poor prognosis of patients with PCa. CS may play an essential role in the progression of $\mathrm{PCa}$, which might be partially associated with its regulation on the lipid metabolism and mitochondrial function. In addition, more experiments are required to study the molecular mechanisms underlying the biological functions of CS in PCa.

\section{Acknowledgment}

We thank Prof. Zhang from the Institute of Chinese Materia Medica, China Academy of Chinese Medical Sciences, Beijing, China, for providing writing assistance. We also thank the BioTree Company, Shanghai, China, for the help of the metabolic assay.

\section{Funding}

National Natural Science Foundation of China, Grant/Award Number: 81874099, 81600620, 81571427, 81802567; Science and Technology Project of Guangdong Province, Grant/Award Number: 2018A030313668; Fundamental Research Funds for Central Universities, Grant/Award Number: 2018MS18, 21618306; Guangzhou Municipal Science and Technology Project, Grant/Award Number: 201803040001, 201707010291, 201710010081; The Science Foundation of Guangzhou First People's Hospital, Grant/Award Number: Q2019007, Q2019020.

\section{Disclosure}

The authors declare that they have no possible conflicts of interest.

\section{References}

1. Siegel RL, Miller KD, Jemal A. Cancer statistics, 2019. CA Cancer J Clin. 2019;69(1):7-34. doi:10.3322/caac.21551

2. Bray F, Ferlay J, Soerjomataram I, et al. Global cancer statistics 2018: GLOBOCAN estimates of incidence and mortality worldwide for 36 cancers in 185 countries. CA Cancer J Clin. 2018;68 (6):394-424. doi: 10.3322/caac.21492

3. Negoita S, Feuer EJ, Mariotto A, et al. Annual report to the nation on the status of cancer, part II: recent changes in PCa trends and disease characteristics. Cancer. 2018;124(13):2801-2814. doi:10.1002/ cncr.31549

4. Eidelman E, Twum-Ampofo J, Ansari J, et al. The metabolic phenotype of prostate cancer. Front Oncol. 2017;7:131. doi:10.3389/ fonc.2017.00131

5. Costello LC, Feng P, Milon B, et al. Role of zinc in the pathogenesis and treatment of PCa: critical issues to resolve. Prostate Cancer Prostatic Dis. 2004;7(2):111-117. doi:10.1038/sj.pcan.4500712

6. Costello LC, Franklin RB. A comprehensive review of the role of zinc in normal prostate function and metabolism; and its implications in PCa. Arch Biochem Biophys. 2016;611:100-112. doi:10.1016/j. abb.2016.04.014

7. Wiegand G, Remington SJ. Citrate synthase: structure, control, and mechanism. Аnпu Rev Biophys Biophys Chem. 1986;15:97-117. doi:10.1146/annurev.bb.15.060186.000525

8. Chen L, Liu T, Zhou J, et al. Citrate synthase expression affects tumor phenotype and drug resistance in human ovarian carcinoma. PLoS One. 2014;9(12):e115708. doi:10.1371/journal. pone. 0115708

9. Schlichtholz B, Turyn J, Goyke E, et al. Enhanced citrate synthase activity in human pancreatic cancer. Pancreas. 2005;30(2):99-104. doi:10.1097/01.mpa.0000153326.69816.7d

10. Lin CC, Cheng TL, Tsai WH, et al. Loss of the respiratory enzyme citrate synthase directly links the warburg effect to tumor malignancy. Sci Rep. 2012;2:785. doi:10.1038/srep00785

11. Mycielska ME, Broke-Smith TP, Palmer CP, et al. Citrate enhances in vitro metastatic behaviours of PC-3M human PCa cells: status of endogenous citrate and dependence on aconitase and fatty acid synthase. Int $J$ Biochem Cell Biol. 2006;38(10):1766-1777. doi:10.1016/j.biocel.2006.04.008

12. Miyamoto DT, Zheng Y, Wittner BS, et al. RNA-Seq of single prostate CTCs implicates noncanonical Wnt signaling in antiandrogen resistance. Science. 2015;249(6254):1351-1356. doi:10.1126/ science.aab0917

13. Liu ZZ, Han ZD, Liang YK, et al. TRIB1 induces macrophages to M2 phenotype by inhibiting IKB-zeta in PCa. Cell Signal. 2019;59:152-162. doi:10.1016/j.cellsig.2019.03.017

14. Jia Zhuo Y, Zhen Liu Z, Wan S, et al. Enhanced expression of SRPK2 contributes to aggressive progression and metastasis in prostate cancer. Biomed Pharmacother. 2018;102:531-538. doi:10.1016/j. biopha.2018.03.079

15. Thakur S, Daley B, Gaskins K, et al. Metformin targets mitochondrial glycerophosphate dehydrogenase to control rate of oxidative phosphorylation and growth of thyroid cancer in vitro and in vivo. Clin Cancer Res. 2018;24(16):4030-4043. doi:10.1158/1078-0432.CCR-17-3167

16. Passalacqua KD, Lu J, Goodfellow I, et al. Glycolysis Is an Intrinsic factor for optimal replication of a norovirus. MBio. 2019;10(2): e02175-18. doi:10.1128/mBio.02175-18

17. Giunchi F, Fiorentino M, Loda M. The metabolic landscape of prostate cancer. Eur Urol Oncol. 2019;2(1):28-36. doi:10.1016/j. euo.2018.06.010 
18. Schug ZT, Vande Voorde J, Gottlieb E. The metabolic fate of acetate in cancer. Nat Rev Cancer. 2016;16(11):708-717. doi:10.1038/nrc.2016.87

19. Lloyd MD, Yevglevskis M, Lee GL, et al. $\alpha$-Methylacyl-CoA racemase (AMACR): metabolic enzyme, drug metabolizer and cancer marker P504S. Prog Lipid Res. 2013;52(2):220-230. doi:10.1016/j. plipres.2013.01.001

20. De Nunzio C, Aronson W, Freedland SJ, et al. The correlation between metabolic syndrome and prostatic diseases. Eur Urol. 2012;61(3):560-570. doi:10.1016/j.eururo.2011.11.013

21. Sreekumar A, Poisson LM, Rajendiran TM, et al. Metabolomic profiles delineate potential role for sarcosine in prostate cancer progression. Nature. 2009;457(7231):910-914. doi:10.1038/nature07762

22. Cardaci S, Ciriolo MR. TCA cycle defects and cancer: when metabolism tunes redox state. Int J Cell Biol. 2012;2012:161837. doi: $10.1155 / 2012 / 161837$

23. Frezza C, Gottlieb E. Mitochondria in cancer: not just innocent 1 bystanders. Semin Cancer Biol. 2009;19:4-11. doi:10.1016/j. semcancer.2008.11.008

24. Gaude E, Frezza C. Defects in mitochondrial metabolism and cancer. Cancer Metab. 2014;2:10. doi:10.1186/2049-3002-2-10

25. Simonnet H, Alazard N, Pfeiffer K, et al. Low mitochondrial respiratory chain content correlates with tumor aggressiveness in renal cell carcinoma. Carcinogenesis. 2002;23:759-768. doi:10.1093/carcin/ 23.5.759
26. Dashty M. A quick look at biochemistry: carbohydrate metabolism. Clin Biochem. 2013;46(15):1339-1352. doi:10.1016/j.clinbiochem. 2013.04.027

27. Mao J, DeMayo FJ, Li H, et al. Liver-specific deletion of acetyl-CoA carboxylase 1 reduces hepatic triglyceride accumulation without affecting glucose homeostasis. Proc Natl Acad Sci U S A. 2006;103 (22):8552-8557. doi:10.1073/pnas.0603115103

28. Barber MC, Price NT, Travers MT. Structure and regulation of acetyl-CoA carboxylase genes of metazoa. Biochim Biophys Acta. 2005;1733(1):1-28. doi:10.1016/j.bbalip.2004.12.001

29. Röhrig F, Schulze A. The multifaceted roles of fatty acid synthesis in cancer. Nat Rev Cancer. 2016;16(11):732-749. doi:10.1038/ nrc. 2016.89

30. Ray U, Roy SS. Aberrant lipid metabolism in cancer cells - the role of oncolipid-activated signaling. FEBS J. 2018;285(3):432-443. doi:10.1111/febs.14281

31. Beloribi-Djefaflia S, Vasseur S, Guillaumond F. Lipid metabolic reprogramming in cancer cells. Oncogenesis. 2016;5:e189. doi:10.1038/oncsis.2015.49

32. Vamecq J, Dessein AF, Fontaine M, et al. Mitochondrial dysfunction and lipid homeostasis. Curr Drug Metab. 2012;13(10):1388-1400. doi: $10.2174 / 138920012803762792$

\section{Publish your work in this journal}

Cancer Management and Research is an international, peer-reviewed open access journal focusing on cancer research and the optimal use of preventative and integrated treatment interventions to achieve improved outcomes, enhanced survival and quality of life for the cancer patient.
The manuscript management system is completely online and includes a very quick and fair peer-review system, which is all easy to use. Visit http://www.dovepress.com/testimonials.php to read real quotes from published authors. 